\title{
68 \\ Preparing Teachers to Teach Science and Mathematics with Technology
}

\author{
Margaret L. Niess \\ Science and Mathematics Education, Oregon State University, Corvallis, OR, USA \\ niessm@ucs.orst.edu
}

Keywords: teacher education, teaching methods, integration of ICT, secondary education, pedagogy

\begin{abstract}
Oregon State University has developed a teacher preparation model for preparing teachers to teach with technology. Student teachers develop extensive plans for implementing hands-on technology activities integrated with teaching science or math content. Following instruction, their reflections are directed toward student learning of science and math with technology. Does the technology support or hinder conceptual development? Ultimately, they recognise enhanced instructional outcomes related to the science and/or math of the technology. Recognition of this key factor enhances their understanding of integrating technology in a manner that extends student learning beyond traditional science or math outcomes.
\end{abstract}

\section{INTRODUCTION}

Emergence into the $21^{\text {st }}$ century features tools that are different, communication that is different, information that is different, and work that is different. Education proposes to provide the avenue for success in an increasingly globally competitive marketplace. Teachers are asked to prepare students 'to live, learn, and work successfully in an increasingly complex and information-rich society' (ISTE 2000). This growing recognition highlights that learning must be different incorporating computer-based, electronic technologies, and that learning to use these technologies must not be separated from learning and communicating in the context of the academic 
subject areas. Given this perspective, how teachers have learned their content is not necessarily the way the topics should be taught in the $21^{\text {st }}$ century.

New, ambitious mathematics and science standards propose a scientifically and mathematically rich curriculum where technology is an essential component of the learning environment, not only in the curriculum but also in the instruction. Similarly, new technology standards for students and teachers challenge educators to integrate technology throughout their instruction. The direction of these standards emphasises that electronic technologies are "an integral component or tool for learning and communications within the context of academic subject areas" such as mathematics and science.

The question remains: how are teacher preparation programs integrating technology into their courses and program outcomes to prepare teachers at a time when electronic technologies will significantly impact and change teaching and learning in K-12 science and mathematics classrooms? Recent calls have identified not only the need for research on inserting technology as a viable and integral part of the general education curriculum, but also for research to identify essential professional development for teachers to make this shift. These efforts underscore the need for identifying, testing and sharing different models that prepare teachers to teach with technology as an integral tool in teaching and learning.

\section{THEORETICAL BACKGROUND}

Numerous studies have yielded consistent findings on the difference in the thoughts and instructional practices of expert and novice teachers (Borko and Livingston 1989, Leinhardt 1989). As novices, pre-service teachers are involved in integrating new knowledge into their prior understandings for teaching the subject. From a constructivist perspective, as novices, their actions largely stem from personal experiences, an understanding largely based on having been taught their subject in particular ways. With teacher preparation program experiences and instructional practice, their beliefs, knowledge and thinking mature. Comprehensive reviews of research on teachers thought processes related to instructional practice have identified three important components: planning during the pre-active (prior to teaching) stage (Clark and Yinger 1979); monitoring and regulating during the interactive (teaching) stage (Fogarty et al. 1983); and assessing and revising in the post-active (after teaching) stage (Ross 1989). However, the development of an integrated knowledge structure more typical of expert teachers requires experiences focused on an integration of these stages. Pre- 
service teachers need experiences that specifically relate to or interconnect with their thinking in these three stages; the additional experiences provide critical actions in support of the growth and maturation of the pre-service teachers' decision making and thinking skills and abilities (Shavelson 1986).

With respect to teaching with technology, teacher preparation programs typically provide a course about technology perhaps with a unit or discussion on teaching with technology and a requirement that students design lessons to teach with the technologies. However, experiences that require the integration of the three stages of decision-making and thinking are typically missing. The purpose of this paper is to investigate a new model for preparing teachers to integrate teaching with technology within the context of teaching of science and mathematics. This exploratory study examines a model that emphasises the interaction of the three stages of decision-making to support connections more typical of the thinking processes of expert teachers when thinking about integrating technology in teaching science and mathematics. Two questions guided this research.

1. What are the key characteristics of the model of a preservice teacher preparation program focused on integrating teaching with technology in teaching science and mathematics?

2. What are the characteristics that describe successful preservice teachers in planning, implementing, and reflecting on instruction integrating technology in teaching science/mathematics?

To explore these questions, 22 students (admitted as a cohort group July 1999-June 2000) participated in the graduate level, subject specific (mathematics/science) teacher preparation program. For admission, students had earned a Bachelor's degree with the equivalent of a major in the teaching area (e.g. biology). Once admitted to the program, students were referred to as 'interns' because of the extensive internship requirements in the program.

\section{THE PROGRAM}

Oregon State University offers a one-year, 54-quarter hour, graduate level, subject-specific science and mathematics teacher preparation program for grades 3-12 focused on the integration of technology throughout the year. The overall conceptual framework of the program emphasises the development of an integrated knowledge structure of the various domains of knowledge critical for effective teaching, a framework described as Knowledge Growth in Teaching (Shulman 1986). With an emphasis on the integration of six domains of knowledge (subject matter, learners, schools, curriculum, pedagogy, and pedagogical content), the program supports the 
professional development of teachers in preparation to address and confront the multiplicity of decisions required during the preactive, interactive and post-active phases of teaching. Within this framework, key themes are emphasised in specific courses and practical experiences: (1) researchedbased teaching and learning; (2) technology integration; (3) pedagogical content knowledge (PCK) development; and (4) instructional practice integrated with campus-based coursework.

The research-based teaching and learning theme is emphasised primarily in the Methods sequence and the Analysis of Classrooms sequence. The summer Methods course introduces interns to writing lesson plans that demonstrate a clear introduction, body or development, closure with estimated times, the content main points, planned key questions with expected answers, plans for explicit student involvement, instructional logistics, plans for extra time and early finishers, and plans for evaluation and homework. The subsequent Methods courses emphasise research-based instructional methods/modes, contemporary mathematics/science curriculum goals, classroom management instructional planning, and assessment of student achievement. The Analysis of Classrooms sequence applies observational techniques and effective teaching research to enhance interns' understandings of the complexities of classrooms and the school culture.

The technology integration theme emphasises preparing interns with skills in using electronic technologies, while also preparing them to engage their students in learning using appropriate computer-based technologies that support the development of science and mathematics knowledge. The Technology courses are focused around the pre-active, interactive, and postactive stages of teaching to provide interns with methods, abilities, and skills in teaching with technologies, preparing them to make informed decisions about which technologies to use for teaching specific topics in the curriculum. They receive direct instruction in the use of technologies in teaching mathematics and science over the four terms. The instruction models teaching specific science or mathematics concepts with technology. In the Technology and Pedagogy I course, interns are required to develop plans to teach with technology in a sequence of lessons (3-5 instructional days to be taught during their full-time internship). Real-time data collection devices are required as the technology. Since not all classrooms have access to such equipment, a classroom set is available. Interns are expected to prepare a planning notebook describing their proposed plans for teaching with the technology; the plans contain the rationale for teaching the particular lessons, goals/objectives, calendar, materials, detailed instructional plans, and evaluation plans. The plans must involve a pre-lab that includes a demonstration preparing students for working with the technology, a handson lab where students in groups collect data for investigating specific 
math/science concepts or problems, and a debrief or closure to the activity with some evaluation of the students' progress in meeting the objectives of the lessons. Faculty provide extensive reviews of the lessons and determine each intern's preparation to teach with technology. Interns are expected to make adjustments as recommended and have their university supervisor and mentor teacher review their work before actually teaching during their fulltime internship (or student teaching). After teaching the technology sequence, interns are expected to revise and expand the planning notebook to reflect the actual teaching experience, adding their daily reflections on the lessons and an extensive analysis of teaching/learning. In this final section, the interns prepare an analysis of: (1) each student's understanding of the concept with the use of the technology in assisting in learning the concept, (2) the success of the integration of the technology in the lessons (overall as well as recommendations for changes), and (3) their own teaching while integrating technology. This final notebook is submitted in the Technology and Pedagogy II class, a class to extend the notion of teaching with technologies, particularly focusing on pedagogical concerns identified during the full-time internship. More specifically, this course highlights PCK aspects of teaching with technology. Concerns are presented about the misconceptions students may gain as a result of learning specific concepts with technology.

The theme of PCK is evident in more than the technology courses. Two classes, one prior the full-time internship and one following, focuses on PCK specifically related to teaching science and mathematics. Interns develop and analyse a variety of representations of subject matter within specific instructional contexts appropriate for different grade levels, different science/math content levels, and different student ability levels. These analytic experiences provide them with additional integrative experiences in the pre-active stage of teaching.

In support of the instructional practice theme, internships are integrated with the campus-based instruction, extending the opportunities to apply their knowledge about teaching, to critically observe classroom instruction, and to reflect on their experiences and developing integrated knowledge base. The interns are expected to plan, teach, and reflect on lessons integrating technology through a variety of instructional practice experiences interspersed throughout the other courses in the program. In the microteaching course, the interns plan and teach lessons, practising specific strategies (inductive, deductive, hands-on/lab, demonstration); one of the four lessons must include teaching with technology. Interns must reflect on the teaching experiences; and after submitting their reflection considering ways to improve the lesson and their own teaching, they are provided with the instructor's evaluations of the lesson plan and the teaching of that lesson. 
These micro-teaching experiences focus the interns on the interactive phase of teaching providing both monitoring and regulating assistance; additionally, the reflective expectations are designed to continually interconnect their thinking in the three stages, preactive, interactive and postactive.

The school-based experiences focus on the preparation of lesson and unit plans, implementation of those plans, active interaction with students, implementation of management strategies, reflection on and revision of instruction, professional communication, and demonstration of content and pedagogical knowledge. The full-time internship (student teaching) takes place over Winter and Spring terms (12 weeks of teaching). During this fulltime experience, the interns teach in multiple courses. Supervisors and mentors are asked to review all plans before teaching, complete weekly clinical supervision visits providing systematic feedback to monitor the interns' progress in teaching. Similarly, mentors and supervisors work with the interns with their technology sequence. Interns are required to reflect in writing following the teaching of each lesson taught.

This pre-service teacher preparation program differs from the traditional model with three, key ways.

1. Instruction with different technologies is specific to learning science/math, a subject specific teacher preparation. Problem-based activities are used to instruct the pre-service teachers in learning about the technology, teaching/learning with the technology, and teaching/learning the specific science/math topic.

2. Assignments and expectations for learning to teach science/math with technology are interwoven among all courses. All faculty members have responsibility to present technology as an integral component for teaching and learning science/math.

3. Interns are required to actually plan, teach, and reflect upon sequences of lessons that involve their students in hands-on work with technology during their full-time internship. Interns are supported by activities that require them to integrate their thinking and decision-making interrelating the pre-active, interactive and post-active stages of teaching.

\section{INTEGRATING TECHNOLOGY IN TEACHING: KEY FACTORS}

To investigate the model for preparing to integrate technology in this teacher preparation program, systematic course observations were supported with informal interviews and formal meetings with supervisors, faculty, and interns. Collection and analysis of all coursework and assignments provided 
the basis for the previous description of the program identifying the key characteristics of the model. To identify the characteristics of successful interns in teaching with technology, analysis of the data occurred at two stages: (1) the completion of the first six months of the program immediately prior to the full-time internship and (2) the completion of the entire preservice program (in June).

At each stage, the interns' success and preparation for integrating technology in teaching science/mathematics were assessed. During the first stage, success was determined in terms of the demonstration of the ability to think carefully through the multitude of issues that might arise in teaching with technology. This ability was assessed primarily from the interns' planning notebooks. Interns were provided with extensive feedback on their plans for teaching with technology. In describing the preparation of the intern's for teaching with technology, three areas (knowledge of content, knowledge of technology, knowledge of teaching with technology) were rated using a three point scale: Good, Adequate, or Inadequate. A rating of Good (indicating good preparation for teaching with technology) required a rating of Good in all three areas. The rating of Adequate meant that the ratings in each of the three areas were at least Adequate. The Inadequate rating indicated that at least one of the areas had received an Inadequate rating. The ratings were determined by assessing their plans prior to the fulltime internship and on their revised plans, observations of their teaching, and the interns' reflections on teaching. Comparison of the plans prior to teaching, work during teaching, and the intern's reflective analysis provided the major data source for the second stage. The primary data source for the determination was the final technology experience notebook using similar ratings as with the prior notebook.

At the end of the program, of the 22 interns, 14 were identified as demonstrating good content knowledge in math/science, with technology, and in the integration of technology in teaching math/science; while six were identified as being adequately prepared while two interns were considered as inadequately prepared for teaching with technology. Key factors in the interns' decision making in the pre-active stage included recognition of the time requirement in preparation for teaching with technology in a laboratory setting. For a successful experience, interns needed to attend to the relevance of the lab work, the structure involved in the activities, the methods by which students record and report data, classroom management and evaluation of student work. Time and good organisational skills were essential for designing the hands-on activities, preparing materials with detailed instructions, thoroughly testing all the equipment and the lab details. Decisions in the interactive stage depended upon careful pre-active stage planning. Without the extensive planning, the interns were focused on 
classroom management and troubleshooting with the equipment rather than engaging student thought during the interactive stage. The post-active stage provided the interns with the greatest learning opportunity - thinking back over their planning and the results of their plans. Work during this stage focused on student learning with the technology, whether the technology supported or hindered concept development. At this point, successful interns recognised the importance of an additional set of outcomes when using the technology - outcomes related to the science and/or math of the technology. Recognition of this key factor focused their thoughts on integrating technology in a manner that enhanced student learning beyond the traditional science or math outcomes. Successful interns were able to integrate technology in their lessons in such as manner as to encourage students to explore science or mathematics in more depth and in ways that involved the theoretical basis of the technology.

\section{SUMMARY}

Teacher preparation programs preparing teachers to teach with technology must focus on the development and enhancement of three key domains of knowledge: knowledge of the subject matter - science or mathematics; knowledge of the technology, including an in depth understanding of the science and/or mathematics embodied in the technology; and knowledge of pedagogy - an understanding of teaching and learning. The one-year graduate program provides a model focused on an integration of these domains of knowledge to support the development of teachers to address and confront the multiplicity of decisions required during the three stages of teaching. Ultimately, the program focused the interns' thought processes on the development of pedagogical content knowledge required in teaching science/mathematics with technology. This highlights key factors for successful experiences: importance of extensive planning and preparation with concern for the content to be taught, the technology to be used, and teaching the content within a technology context (considering learner experiences, needs and skills, curriculum development, and instruction considering classroom implementation and management). Requiring pre-service teachers to actually teach a sequence of lessons provides them with opportunities for reflection that integrate their thinking and decision-making interrelating the pre-active, interactive and post-active stages of teaching, leading to an integrated knowledge structure with respect to teaching their content with technology. Thus, they naturally consider technology as they think about teaching mathematics or science. In one intern's words, "It is clear to me that even if the class did not use the 
technology to learn the topics ... they still would have learned the information. However, by using the technology the students were able to cover some objectives that wouldn't be so easily or quickly met without the use of technology."

\section{REFERENCES}

Borko, H. and Livingston, C. (1989) Cognition and Improvisation: Differences in Mathematics Instruction by Expert and Novice teachers. American Educational Research Journal 26 (4), pp. 473-498.

Clark, C. M. and Yinger, R. J. (1979) Teachers' Thinking. In Research on Teaching, P. L. Peterson and H. J. Walberg (eds.) Berkeley, CA: McCutchan, pp. 231-263.

Fogarty, J., Wang, M., and Creek, R. (1983) A Descriptive Study of Experienced and Novice Teachers' Interactive Instructional Thoughts and Actions. Journal of Educational Research, 77, pp. 22-32.

International Society for Technology in Education (2000) National Educational Technology Standards for Teachers. Eugene, OR: Author.

Leinhardt, G. (1989) Math Lessons: A Contrast of Novice and Expert Competence. Journal for Research in Mathematics Education. 20 (1), pp. 52-75.

Ross, D. D. (1989) First Steps in Developing a Reflective Approach. Journal of Teacher Education, 40 (2), pp. 22-30.

Shavelson, R. J. (1986) Interactive Decision Making: Some Thoughts on Teacher Cognition. Invited address, I. Congreso Internacional, "Pensamientos de los Profesores Y Toma deDecisiones," Seville, Spain.

Shulman, L. S. (1986) Those Who Understand: Knowledge Growth in Teaching. Educational Researcher, 15, pp. 4-14.

\section{BIOGRAPHY}

Margaret Niess is Professor of science and mathematics education and Director of science and mathematics teacher preparation. She has focused on the integration of instructional technology in teaching science and mathematics over the past 20 years and has led the integration of technology in graduate level, preservice teacher preparation (K-12) and in-service teacher preparation under given support from the US West Foundation. She is co-editor of School Science and Mathematics and mathematics section editor of Learning and Leading with Technology. 